\title{
Reduction of intussusception under general anesthesia by hydrostatic technique: the RIGHT technique
}

\author{
Karunesh Chand', Ravi Patcharu ${ }^{1 *}$ (D), Badal Parikh² and Arun Kumar Yadav ${ }^{3}$
}

\begin{abstract}
Background: Intussusception is the one of the commonest causes of intestinal obstruction requiring urgent attention in early childhood. There is no gold standard of non-operative reduction. We report our 6 years' experience in non-operative reduction using our "RIGHT" (Reduction of Intussusception under General anesthesia using Hydrostatic Technique) technique, emphasizing the need to perform the procedure in the operating room (OR) under general anesthesia. This prospective observational study covering the period from July 2014 till May 2020 included patients diagnosed with intussusception. Hydrostatic reduction was performed in the OR under general anesthesia by infusing a saline enema and the reduction was confirmed by ultrasound.
\end{abstract}

Results: Forty-eight patients underwent reduction using the RIGHT technique. Successful reduction was achieved in 44 (91.6\%) patients. Four (8.3\%) patients needed surgery, three (6.2\%) due to failed reduction and one (2.0\%) due to perforation. One (2.2\%) patient developed a recurrence.

Conclusions: The "RIGHT" technique is a combination of the best available techniques of reduction of intussusception. It ensures patient safety by being performed in the OR, being pain free, avoiding radiation, avoiding the risk of aspiration associated with sedation, and also being able to immediately address a failure of reduction or a complication by surgical exploration.

Keywords: Hydrostatic reduction, Saline enema, Non-operative reduction, Ultrasound guided, Operating room, RIGHT technique

\section{Background}

Intussusception is the one of the commonest cause of intestinal obstruction requiring urgent attention in neonatal and early childhood. Ileocolic intussusception in which the ileum telescopes into the colon is the commonest variety. If left undiagnosed or misdiagnosed and untreated, it may turn fatal due to gangrene and sloughing off of ileum leading to perforation peritonitis. Various methods of reduction have been tried for the last 300 years depending on available knowledge and resources of the era. Presently, the treatment options

\footnotetext{
* Correspondence: ravipatcharu@gmail.com

${ }^{1}$ Department of Pediatric Surgery, Army Hospital (Research \& Referral), New Delhi 110010, India

Full list of author information is available at the end of the article
}

available are a permutation and combination of either of operative, hydrostatic, or pneumatic reduction, under fluoroscopy or ultrasound (USG) guidance, or laparoscopic guidance or manipulation. A combination of these modalities gives us $8-10$ treatment options which are practiced by different surgeons based on their choice, comfort, and available resources.

The presence of multiple treatment options for a particular entity reveals that there is no gold standard of treatment. Surprisingly, all these methods have been proven to be equally efficacious, hence defining the best treatment option is still elusive. Our experience is that non-operative reduction attempted in the radiology suite is quite unsafe and uncomfortable for the patient and the parents, messy for the operators, and has a

\section{Springer Open}

(c) The Author(s). 2021 Open Access This article is licensed under a Creative Commons Attribution 4.0 International License, which permits use, sharing, adaptation, distribution and reproduction in any medium or format, as long as you give appropriate credit to the original author(s) and the source, provide a link to the Creative Commons licence, and indicate if changes were made. The images or other third party material in this article are included in the article's Creative Commons licence, unless indicated otherwise in a credit line to the material. If material is not included in the article's Creative Commons licence and your intended use is not permitted by statutory regulation or exceeds the permitted use, you will need to obtain permission directly from the copyright holder. To view a copy of this licence, visit http://creativecommons.org/licenses/by/4.0/. 
significant delay in immediate surgical management in case of failure or complication.

The aim of the present study is to find an ideal environment which is very safe for the patient, comfortable for the operators and flexible enough to promptly deal with any complication.

\section{Methods}

This prospective observational study was conducted from July 2014 to May 2020 at a tertiary care pediatric surgery center. All children suspected to have intussusception on clinical presentation and examination and confirmed by USG performed by a senior faculty of radiology were included in the study. Meticulous records were kept so as not to miss any case presenting with intussusception to reduce bias. There were a total 48 patients during the study duration, and all were included in the present study. Data collected included patient demographics, presentation, symptoms, USG findings, procedural information, failure rate, and recurrence rate. Patients with evidence of perforation or peritonitis and parents refusing to consent for the procedure were planned to be excluded from the study. In our study, all patients diagnosed with intussusception were included, as none of them had any exclusion criteria. The Institutional Ethics Committee approved the study.

All patients diagnosed with intussusception were admitted to a single hospital. After adequate fluid resuscitation and stabilization, consent was obtained from parents and patient was shifted to the operating room (OR). The anesthetist administered general anesthesia (GA). The pediatric surgery team consisted of either of two pediatric surgeons alternatively, each of whom were practicing consultants at the tertiary care center, along with a pediatric anesthesiologist, and the OR matron was scrubbed and a laparotomy trolley was arranged and kept ready for immediate operative intervention in case of a complication in the form of perforation or a failure of reduction. The two surgeons performed equal surgeries. Both the surgeons are experienced and practicing surgery for more than a decade. The technique was standardized as follows: the patient was placed in a supine position with hips partially abducted and knees partially flexed. A 16-Fr Foley catheter was inserted per rectum for $7-10 \mathrm{~cm}$, and the balloon was inflated with $20 \mathrm{ml}$ normal saline (NS). The radiologist localized the intussusception using USG and provided intraoperative guidance. The Foley catheter was connected to NS infusion warmed to $37^{\circ} \mathrm{C}$ and set hanging $1 \mathrm{~m}$ above the level of the OR table. NS was allowed to run at full flow, and the progress of the water column into the colon was monitored by USG. Real-time monitoring of reduction of intussusception was done by USG by the radiologist. The time taken for reduction and the volume of fluid infused were recorded.

The objective USG criteria for reduction were chosen for reducing measurement bias which were:

1. Disappearance of the intussusceptum after passing through ileocecal valve.

2. Visualization of reflux of fluid and air bubbles through the caecum and ascending colon into the ileum across the ileocecal valve.

3. Demonstration of fluid distended ileum.

4. Absence of intussusceptum noted during the postevacuation USG examination.

Once complete reduction was achieved, the fluid was evacuated from the colon by connecting a drainage bag to the Foley catheter. USG was performed again on the table to rule out a residual lesion and also to look for free fluid in the pelvis and the hepatorenal pouch to rule out any small perforation during reduction. USG was repeated after $12 \mathrm{~h}$ to look for recurrence, in the absence of which, feeds were started and the patient was discharged. Criterion for abandoning the procedure was failure to progress for $10 \mathrm{~min}$ on two attempts $15 \mathrm{~min}$ apart or any complication arising during the procedure. We follow this criteria as we believe that GA itself aids in reduction of intussusception and if two attempts have been unsuccessful at reduction, then further attempts are less likely to succeed and surgical intervention would be ideal.

The data was collected in paper and pencil form and was entered into the excel sheet. The quantitative variables were described as mean and SD (standard deviation) or median and IQR (interquartile range) after checking for normality of the data. The qualitative variables were described as number and percentages. Appropriate statistical test were used to find association or correlation among variables. The data was analyzed using StataCorp. 2013. Stata Statistical Software: Release 13. College Station, TX: StataCorp LP. The $p$ value of less than 0.05 was taken as significant.

\section{Results}

During the study period, we enrolled 48 patients with intussusception $(\mathrm{M} / \mathrm{F}, 33 / 15$; age mean $=16.75$ months; range $6-60$ months). The most common age at presentation was between 12 and 24 months of age. All patients presented with pain and vomiting. Twenty-one of $48 \mathrm{pa}-$ tients also had rectal bleeding. The duration of symptoms in most patients was between 24 and $48 \mathrm{~h}$. USG revealed ileocolic intussusception in all patients. The complete list of demographic profile, presentation, and procedure information is shown in Table 1 . Hydrostatic reduction was attempted in all patients in the OR under 
Table 1 Demographic profile, clinical presentation, and procedure information

\begin{tabular}{ll}
\hline & Number of patients and percentage \\
\hline Total number of patients & $N=48$ \\
Males & $33(68.8 \%)$ \\
Females & $15(31.2 \%)$ \\
Age & \\
$<12$ months & $20(41.6 \%)$ \\
12-24 months & $23(47.9 \%)$ \\
$>24$ months & $5(10.4 \%)$ \\
Duration of symptoms & \\
$<24 \mathrm{~h}$ & $6(12.5 \%)$ \\
$24-48 \mathrm{~h}$ & $30(62.5 \%)$ \\
$>48 \mathrm{~h}$ & $12(25 \%)$ \\
Clinical presentation & \\
Pain & $48(100 \%)$ \\
Rectal bleeding & $21(43.7 \%)$ \\
Vomiting & $48(100 \%)$ \\
Palpable abdominal mass & $19(39.5 \%)$ \\
USG findings & \\
Ileocolic intussusception & $48(100 \%)$ \\
Volume of fluid used for reduction & \\
$500-1000$ ml & $31(64.5 \%)$ \\
1000-2000 ml & $17(35.4 \%)$ \\
Time taken for reduction & \\
\hline $5-10$ min & $24(54.5 \%)$ \\
\hline
\end{tabular}

GA. Complete reduction without any complication was achieved in 44 of $48(91.6 \%)$ patients. In 3 of 48 (6.2\%) patients, reduction could not be achieved by the hydrostatic technique; hence, surgical exploration was carried out immediately. The cause of irreducibility in one patient (patient A) aged 42 months was appendicocecal intussusception, in which whole of the appendix had intussuscepted into the caecum and only the tip was visible (Fig. 1). As the radiologist was sure that there was incomplete reduction, surgical exploration was performed and the intussusception was manually disimpacted and appendicectomy was done. In the second patient (patient B) aged 18 months, there was Meckel's diverticulum causing ileo-ileo colic intussusception which could not be reduced by hydrostatic method. This diagnosis also was made intraoperatively after a failed hydrostatic reduction. In this patient, Meckel's diverticulum was excised and end-to-end ileo-ileal anastomosis was performed. In the third patient (patient $\mathrm{C}$ ) aged 60 months, after failed reduction, a laparotomy was performed and a polyp was found in the terminal ileum which looked suspicious so excision of ileal segment was done, which on histopathological examination was diagnosed as non-Hodgkin's lymphoma. In 1 of 48 (2\%) patients (patient D) who was 6 months old, the intussusception could not be reduced (Fig. 2) as there was a colonic perforation while attempting hydrostatic reduction (Fig. 3). This patient was immediately managed with surgical exploration, resection of the intussusception, and repair of colonic perforation. The complete list of demographic profile, presentation, and procedure information of these four patients is shown in Table 2.

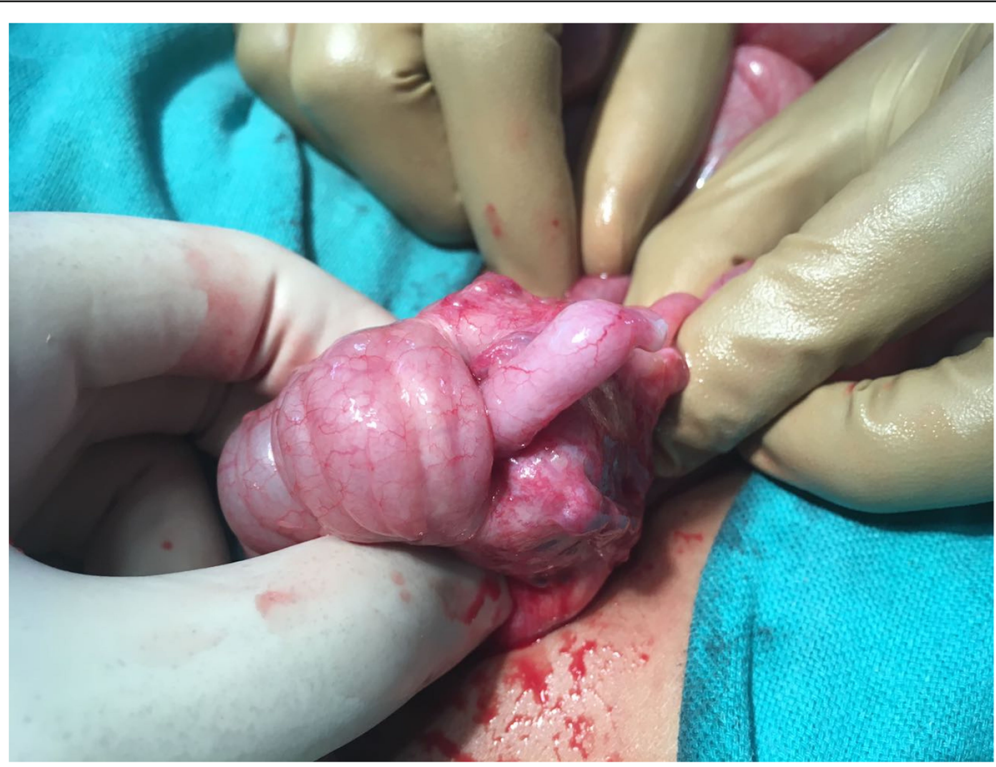

Fig. 1 Patient A with appendicocecal intussusception 


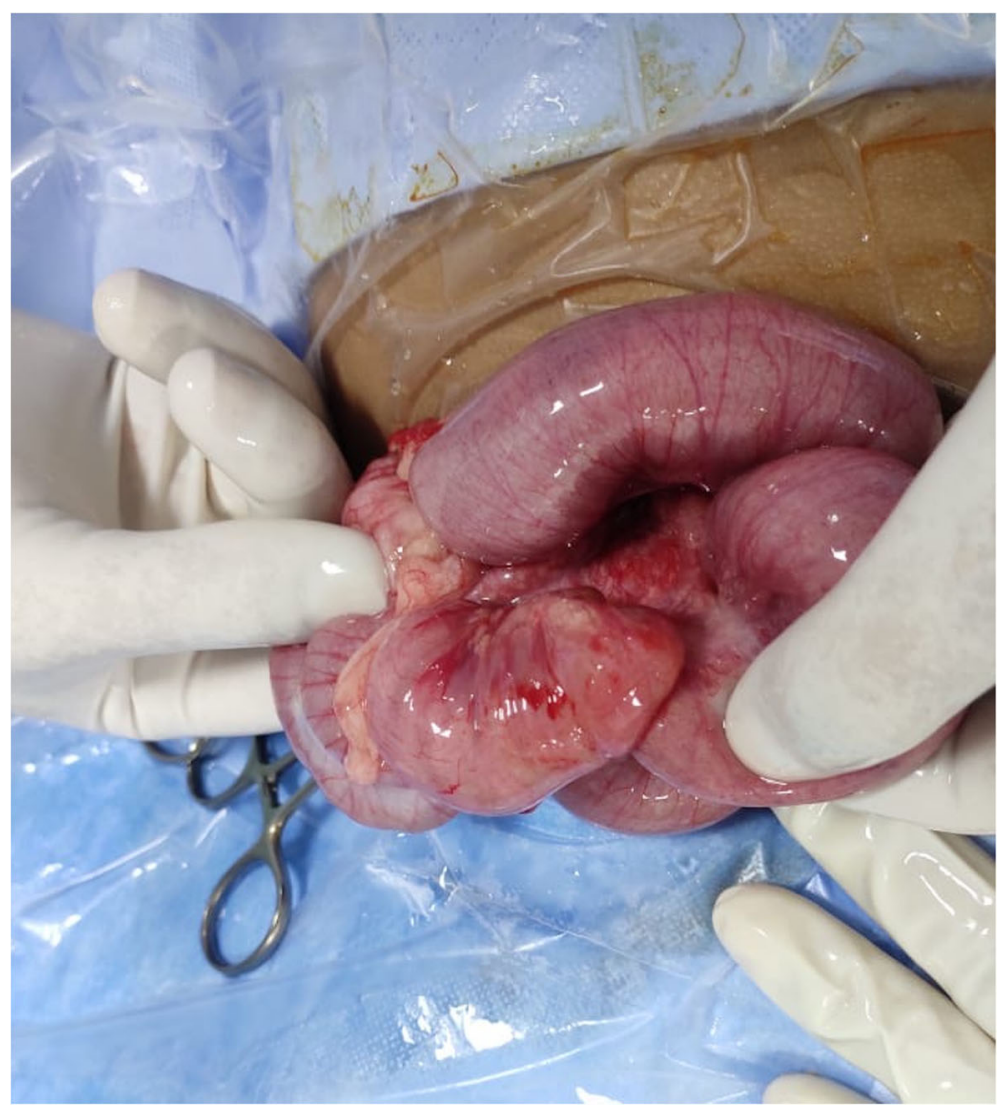

Fig. 2 Patient D with failed non-operative reduction

In all the three cases in which there was failure of the procedure, lead points were present, necessitating surgery. One of $44(2.2 \%)$ patients in whom non-operative reduction could be achieved had recurrence after 4 months of initial reduction, which was again reduced hydrostatically. The child was kept on follow-up and did not have any re-recurrence over a period of 4 years in the duration of the present study.

In this study, the success rate of reduction was $91.6 \%$, the recurrence rate was $2.2 \%$, and the complication rate was $2 \%$. The period of follow-up ranged from the shortest being 1 month to the longest being 6 years.

The correlation matrix is given in Table 3. Age was not correlated with duration, volume of fluids, and time for recovery. Symptoms duration is correlated with both volume of fluids used and time for recovery (Pearson's correlation coefficient $0.5(p$ value $=0.0001)$ and $0.5(p$ value $=0.0002$ )

\section{Discussion}

An ideal treatment for intussusception can be defined as one that is efficacious, safest, and painless for the patient, comfortably performed by the user, replicable, and avoids delay in treatment of possible complications.
Intussusception was first described by Paul Barbette in 1674 and was further characterized by John Hunter in 1793 [1]. Various methods of reduction both operative and non-operative have been tried over the last 300 years [2]. In 1952, Ravitch and Mc Cune published a landmark series in which they used barium sulfate enema to diagnose as well as reduce intussusception, calling this "hydrostatic reduction." They reported $73.6 \%$ success rate, no deaths, and $5.55 \%$ recurrence rate [3], after which attention shifted to non-operative reduction. The successful reduction of intussusception by saline enema under real-time sonography guidance was first described in 1982 by Kim et al. [4].

The various methods of non-operative reduction are pneumatic or hydrostatic, under fluoroscopy, or USG guidance done in the radiology suite either by surgeons themselves or assisted by a radiologist. In the radiology suite, this procedure is generally performed on an awake child or with minimal sedation used on an ad hoc basis [4]. All these procedures have variable success rates with no defined gold standard of treatment. Treatment is in accordance with the operator's comfort and availability of resources. Surgical exploration remains a fallback procedure in case of failure or complication. 


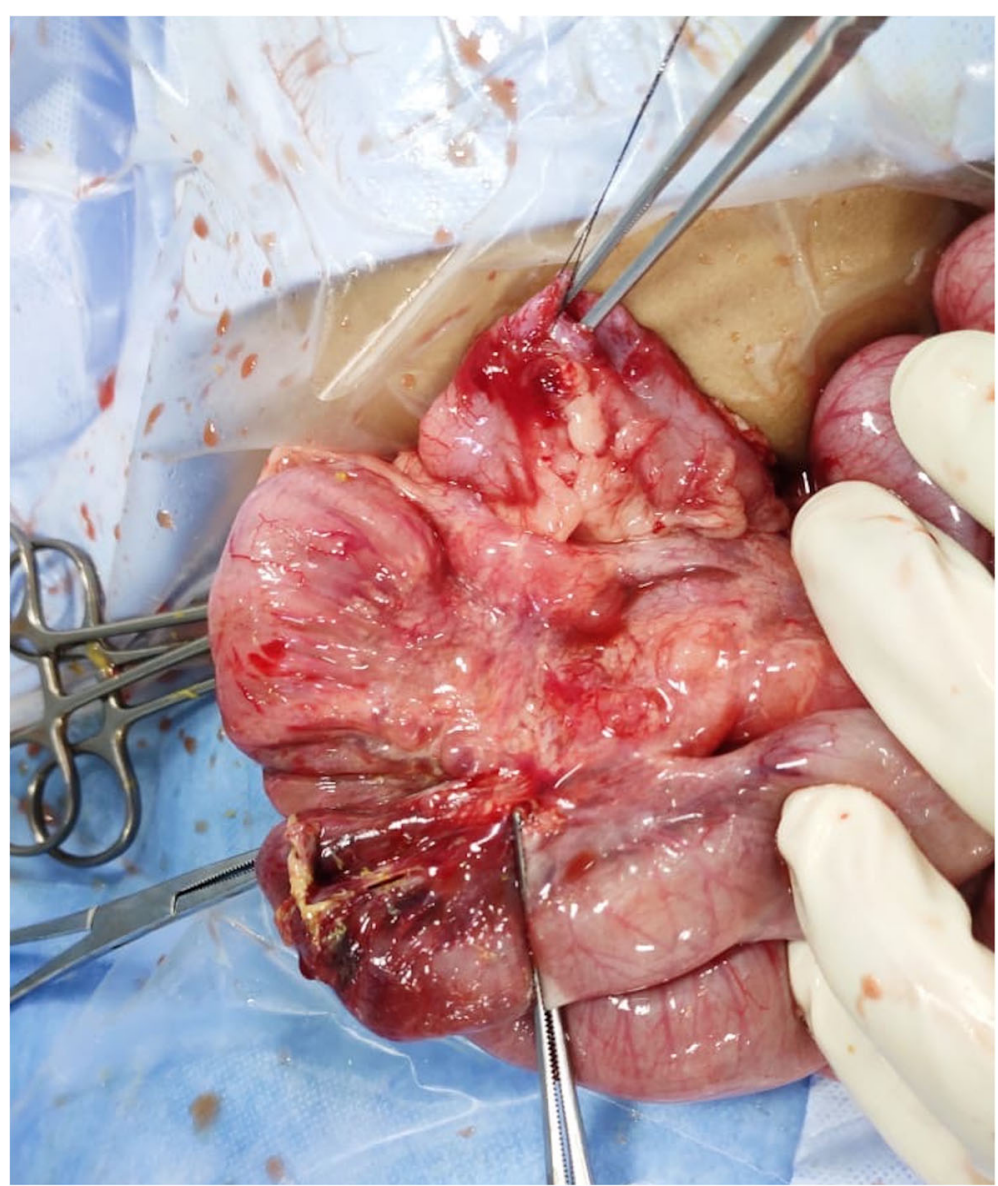

Fig. 3 Patient D with colonic perforation (marked with silk) and manually reduced necrotic intussusceptum

Table 2 Demographic features, clinical presentation, and procedure information of patients with failed non-operative reduction/ perforation

\begin{tabular}{|c|c|c|c|c|}
\hline & Patient A & Patient B & Patient C & Patient D \\
\hline $\begin{array}{l}\text { Reason for } \\
\text { surgical } \\
\text { intervention }\end{array}$ & Failed reduction & Failed reduction & Failed reduction & Bowel perforation \\
\hline $\begin{array}{l}\text { Intraoperative } \\
\text { finding }\end{array}$ & $\begin{array}{l}\text { Appendicocecal } \\
\text { intussusception }\end{array}$ & Meckel's diverticulum & Hodgkin's lymphoma & Colonic perforation and necrotic intussusceptum \\
\hline Age (months) & 42 & 18 & 60 & 6 \\
\hline $\begin{array}{l}\text { Duration of } \\
\text { symptoms } \\
\text { (hours) }\end{array}$ & 48 & 38 & 36 & 72 \\
\hline $\begin{array}{l}\text { Clinical } \\
\text { presentation }\end{array}$ & $\begin{array}{l}\text { Pain } \\
\text { Vomiting }\end{array}$ & $\begin{array}{l}\text { Pain } \\
\text { Vomiting } \\
\text { Rectal bleeding }\end{array}$ & $\begin{array}{l}\text { Pain } \\
\text { Vomiting }\end{array}$ & $\begin{array}{l}\text { Pain } \\
\text { Vomiting } \\
\text { Rectal bleeding }\end{array}$ \\
\hline $\begin{array}{l}\text { Volume of fluid } \\
\text { used }\end{array}$ & $2000 \mathrm{ml}$ & $2000 \mathrm{ml}$ & $2000 \mathrm{ml}$ & $1000 \mathrm{ml}$ \\
\hline $\begin{array}{l}\text { Surgical } \\
\text { management }\end{array}$ & $\begin{array}{l}\text { Manual reduction } \\
\text { and } \\
\text { appendectomy }\end{array}$ & $\begin{array}{l}\text { Resection of Meckel's } \\
\text { and end-to-end } \\
\text { anastomosis }\end{array}$ & $\begin{array}{l}\text { Resection of ileal segment } \\
\text { and end-to-end } \\
\text { anastomosis }\end{array}$ & $\begin{array}{l}\text { Resection of devitalized intussuscepted gut, end-to- } \\
\text { end anastomosis, and primary repair of colonic } \\
\text { perforation }\end{array}$ \\
\hline $\begin{array}{l}\text { Post-surgical } \\
\text { complications }\end{array}$ & $\mathrm{Nil}$ & Nil & $\mathrm{Nil}$ & Nil \\
\hline
\end{tabular}


Table 3 Correlation among age in months, duration, volume of fluid, and time for reduction

\begin{tabular}{lllll}
\hline & Age in months & Symptom duration & Volume of fluids & Time for reduction \\
\hline Age in months & 1 & & & \\
Duration & $-0.07(0.6)$ & 1 & 1 & $0.9(<0.0001)$ \\
Volume of fluids & $-0.04(0.8)$ & $0.5(0.0001)$ & $0.5(0.0002)$ & 1 \\
Time for reduction & $-0.01(0.9)$ & & \\
\hline
\end{tabular}

We consider the treatment of intussusception to be constituted of three arms. First is the "counterforce" (fluid, air or manual). The second is an "observer" who is the radiologist (USG/fluoroscopy), and the third arm is a "fallback team" comprising of the pediatric surgeon and anesthesiologist who are to be ready in the OR for immediate surgical intervention, if needed. In almost all described techniques of non-operative reduction, only two of these three arms have been used, comprising of a surgeon and a radiologist and performed in the radiology suite. But before starting the procedure, the third arm consisting of the anesthetist and OR is always notified and in as many as $10-20 \%$ of cases where failure or complications arise may be pressed into action. We do not consider this to be the best possible treatment scenario. Trying to reduce an intussusception in the radiology suite with a child who is in pain and in the presence of anxious parents leads to added stress to the patient and the parents. The surgeon performing the procedure in the radiology suite is concerned of the possibility of failure of reduction, of causing perforation, and whether the OR would be readily available without any delay, if needed. The apprehensions of the surgeon and the parents can be allayed by performing the procedure in the OR under GA with the surgical team ready for any eventuality. The contention of risk of GA and need for anesthesiologist is unsubstantiated as sedation in radiology suite with limited resources and the risk of aspiration itself warrants for the procedure to be done under the care of an anesthesiologist preferably in the OR. Sedatives usually given during such procedures are benzodiazepines and anti-cholinergics combined with ketamine or fentanyl, doses of which may have to be increased many folds if the procedure is prolonged. The disadvantages of sedation in children can be due to undersedation like causing anxiety to the patient, leading to an uncooperative child, causing difficulty in hydrostatic reduction, and also leaving a psychological impact as complete amnesia is not achieved. Oversedation can cause serious adverse events like respiratory insufficiency and cardiovascular depression besides the risk of aspiration [5]. As per the 2016 update of American Academy of Pediatrics guidelines on monitoring pediatric patients under sedation [6], sedation is known to cause serious adverse events especially in children less than 6 years old. Because the intended level of sedation may be exceeded, the person monitoring needs to be well trained in managing pediatric apnea, laryngospasm, and airway obstruction. Hence also the role of a pediatric anesthesiologist is highlighted. With advancement in pediatric anesthesia, administration of GA to a child has become extremely safe. GA even without muscle relaxants owing to its inherent analgesic and muscle relaxant property relaxes the abdominal muscle tone and voluntary pressure exerted by a crying child. In case of an unsuccessful reduction or complication, precious time is saved as the patient is already in the OR. Thus, in addition to a higher rate of success, GA is safer than sedation [7].

The "RIGHT" technique we describe here, involves three elements: general anesthesia, hydrostatic reduction, and USG guidance, which entails an anesthesiologist, pediatric surgeon, and radiologist working in tandem. Reduction of intussusception under GA has been reported in a few studies, but has not been used as a protocol in management. Chatterejee et al. described a technique of hydrostatic reduction assisted manually after performing a laparotomy which can be used by surgeons in resource challenged situations where USG or fluoroscopy is unavailable [8]. Purenne et al. [7] showed that the success rate of reduction by air enema increased when the procedure was done under GA when compared to sedation. However, they performed the procedure in the radiology suite and in cases where surgery was required, the anesthesia was maintained, and the patient was shifted to the OR. Collins et al. [9] in their study achieved successful reduction under GA in those cases which had one failed attempt under sedation. They proposed that GA reduces abdominal wall muscle tone and relaxes a struggling child with abdominal pain, allowing for better conditions for hydrostatic reduction. They also proposed that anestheticinduced reductions in splanchnic blood flow may result in less edema of the bowel wall, which could prevent obstruction and further compromise. Chandrashekharam et al. [2] in their technique done under GA monitored the reduction of intussusception under direct vision after introducing a laparoscope. Digant et al. [10] evaluated the role of USG guidance for hydrostatic reduction using normal saline and concluded that it was an optimal and safe procedure.

In our study, the success rate of 44 out of 48 (91.6\%) is closer to the success rate with hydrostatic reduction 
under ultrasound guidance of $95.5 \%$ as reported by Bai et al. [11] and Wang and Liu [12]. In all the four patients who underwent surgical exploration, there was no time lag as surgical team was scrubbed and ready and the child was already under GA. There was only one recurrence, which was also reduced by the "RIGHT" technique. Thus, our success rate in idiopathic (without lead point) intussusception was $97.7 \%$. The biggest advantage of the "RIGHT" technique is that in the eventuality of a complication, which is life threatening, precious time can be saved in conversion to surgical exploration.

Since this technique requires the simultaneous involvement of the pediatric surgeon, radiologist, and the anesthesiologist and is to be performed in the OR, the technique may not be feasible at a primary or secondary level hospital where availability of the OR and the presence of all three specialists at the same time in an emergency may be difficult. The study has been carried out in a single center. A multi-centric study is recommended to confirm the findings and increase generalizability of the "RIGHT" technique.

\section{Conclusions}

"RIGHT" (Reduction of Intussusception under General anesthesia using Hydrostatic Technique) method is a combination of the best available techniques of nonoperative reduction of intussusception. It ensures utmost patient safety and comfort by being performed in the controlled environment of the OR, being pain free, avoiding radiation exposure, avoiding the risk of aspiration associated with sedation, and also being able to immediately address a failure of reduction or a complication like perforation by surgical exploration without any delay.

\section{Abbreviations}

USG: Ultrasonography; GA: General anesthesia; OR: Operating room; NS: Normal saline

\section{Acknowledgements}

Not applicable

\begin{abstract}
Authors' contributions
$\mathrm{KC}$ was involved in the diagnosis and performed the procedures alternatively with RP. He also wrote the manuscript. RP performed the procedure alternatively with KC He searched the literature and reviewed the manuscript. BP provided anesthesia during the procedures and where surgical intervention was done and also collected clinical data. AKY analyzed the data and did the statistical analysis. All authors discussed and contributed to the final manuscript. All authors have read and approved the manuscript.
\end{abstract}

Funding

No funding received from any source

\section{Ethics approval and consent to participate}

Institutional Ethics Committee of Army Hospital (Research \& Referral), New Delhi approval was obtained with the IEC Registration No: 113/2020. Written informed consent was obtained from the parent of each of the patients who underwent the procedure.

\section{Consent for publication}

Consent for publication was obtained from the parent of the patients in the study.

\section{Competing interests}

The authors declare that they have no competing interests.

\section{Author details}

'Department of Pediatric Surgery, Army Hospital (Research \& Referral), New Delhi 110010, India. ${ }^{2}$ Department of Anesthesiology, Army Hospital (Research \& Referral), New Delhi 110010, India. ${ }^{3}$ Department of Community Medicine, Armed Forces Medical College, Pune 411040, India.

Received: 23 September 2020 Accepted: 4 February 2021

Published online: 05 April 2021

\section{References}

1. Draus JM Jr, Shelgikar CS, Buchino JJ, et al. Lipoma as a pathological lead point in a child with ileocolic intussusception. J Pediatr Gastroenterol Nutr. 2008:47:372-4.

2. Chandrasekharam V, Gazula S, Gorthi RP. Laparoscopy-assisted hydrostatic in situ reduction of intussusception: a reasonable alternative? J Indian Assoc Pediatr Surg. 2011;16:8

3. Ravitch MM, Morgan RH. Reduction of intussusception by barium enema. Ann Surg. 1952;135:596.

4. Flaum V, Schneider A, Ferreira CG, et al. Twenty years' experience for reduction of ileocolic intussusceptions by saline enema under sonography control. J Pediatr Surg. 2016;51:179-82.

5. Arlachov Y, Ganatra RH. Sedation/anaesthesia in paediatric radiology. Br J Radiol. 2012;85(1019):e1018-31. https://doi.org/10.1259/bj/28871143.

6. Coté CJ, Wilson S, American Academy Of Pediatrics, American Academy Of Pediatric Dentistry. Guidelines for monitoring and management of pediatric patients before, during, and after sedation for diagnostic and therapeutic procedures: update 2016. Pediatrics. 2016;138(1):e20161212.

7. Purenne E, Franchi-Abella S, Branchereau S, et al. General anesthesia for intussusception reduction by enema. Pediatr Anesth. 2012;22:1211-5.

8. Chatterjee US, Ghosh A, Basu AK, et al. Intraoperative hydrostatic reduction of intussusception. J Indian Assoc Pediatr Surg. 2008:13:107.

9. Collins DL, Pinckney LE, Miller KE, et al. Hydrostatic reduction of ileocolic intussusception: a second attempt in the operating room with general anesthesia. J Pediatr. 1989;115:204-7.

10. Digant SM, Rucha S, Eke D. Ultrasound guided reduction of an ileocolic intussusception by a hydrostatic method by using normal saline enema in paediatric patients: a study of 30 cases. J Clin Diagnostic Res JCDR. 2012;6: 1722

11. Bai $Y Z$, Bin QR, Da Wang G, et al. Ultrasound-guided hydrostatic reduction of intussusceptions by saline enema: a review of 5218 cases in 17 years. Am J Surg. 2006;192:273-5.

12. Liu S. Enema reduction of intussusception by hydrostatic pressure under ultrasound guidance: a report of 377 cases. J Pediatr Surg. 1988;23:814-8.

\section{Publisher's Note}

Springer Nature remains neutral with regard to jurisdictional claims in published maps and institutional affiliations. 